\title{
Combined process of vibratory processing and oxidation with the use of polymeric environments
}

\author{
Vladimir Ivanov ${ }^{1}$, Sergey Popov ${ }^{1, *}$, Nikolai Dontsov ${ }^{1}$, Nikolai Ryzhkin ${ }^{1}$, Julia Oleynikova ${ }^{1}$, \\ and Julia Denisenko ${ }^{1}$ \\ ${ }^{1}$ Don State Technical University, Gagarin sq., 1, Rostov on Don, 344003, Russia
}

\begin{abstract}
Studies were carried out to combine vibration processing and oxidation in polymer working media, which allowed to combine three technological stages. Characteristic traces of direct and oblique impact of the polymer working medium, along the surface of the metal with oxide film, are determined. Studies of the structure of the nanorelief of the vibrational chemical-mechanical oxide coating and the main parameters of the process are.
\end{abstract}

\section{Introduction}

Vibration processing makes it possible to provide the effect of the combined action of the energy resulting from the mechanical and chemical components of the coating formation process. Vibration processing provides a change in the physical and chemical properties of the surface layer of the part, as well as its activation. Given the versatility of vibration equipment, it can be used not only for coating formation processes, but also for finishing and stripping and hardening operations, which is important because reduces the cost of production [1-7].

\section{Materials and research methods}

The study of the mechanism of formation of an oxide film is based on the methodology for determining the nature of the location, size, depth and shape of processing traces when working in an environment of polymer working media (polyethylene balls) during oxidation and without an oxidizing solution and for establishing the quality of the film, the general appearance of the surface using optical electron microscopic research methods.

In previously published works [8-13] there is information about the formation of the surface layer in the process of vibration processing in the environment of metallic working media. These processes are accompanied by plastic deformation of the surface layers of the metal under conditions of multiple dynamic contact of particles of the working medium with the part.

\footnotetext{
*Corresponding author: spopov1957@yandex.ru
} 
When combining the method of vibration processing and oxidation, the interaction of the polymer working medium and the surface layer of the material being processed is carried out through the interlayer of the formed oxide film and the solution located in the contact zone. According to the theory of chemical oxidation, the formation of an oxide film, its growth is the result of the interaction of the metal with the working solution, which is carried out through the pores of the film formed during the oxidation process.

When applying oxide coatings on aluminum surfaces, the choice of the working medium is primarily determined by its physicochemical properties [14-20].

The working medium must not interact with the process fluid (oxidizing solution). Considering that finishing and oxidation is the final operation in the technological process, the working environment should be light, elastic, and not allow scratches and nicks. Therefore, as a working medium, we used polymeric working mediums $\varnothing 2-3 \mathrm{~mm}$ (Fig. 1). Non-metallic bodies ensure the uniformity of the oxide coating over the entire surface of the workpiece, serve as suppliers of the oxidizing solution to the reaction zone, as well as smoothing irregularities.

Table 1 shows some of the characteristics of polyethylene.

Table 1. Physical and chemical properties of the polymer

\begin{tabular}{|c|c|}
\hline Indicators & Polyethylene \\
\hline Specific weight, $\mathrm{g} / \mathrm{cm}^{3}$ & $0,92-0,95$ \\
\hline Strength limit: & $110-140$ \\
\hline under tension, $\mathrm{kg} / \mathrm{cm}^{2}$, & $860-990$ \\
\hline in compression, $\mathrm{kg} / \mathrm{cm}^{2}$ & 115 \\
\hline bending, $\mathrm{kg} / \mathrm{cm}^{2}$ & 25 \\
\hline Brinell hardness, $\mathrm{kg} / \mathrm{mm}^{2}$ & 2,1 \\
\hline Thermal conductivity at $20^{\circ} \frac{\mathrm{cal} \cdot 10^{-4}}{\mathrm{~cm} \cdot \mathrm{sec}^{0} \mathrm{C}}$ & $-45-100^{\circ}$ \\
\hline Material application temperature limit, ${ }^{\circ} \mathrm{C}$ & 0,01 \\
\hline Water absorption in 24 hours at $20^{\circ} \mathrm{C},{ }^{\circ}$ & racks \\
\hline
\end{tabular}

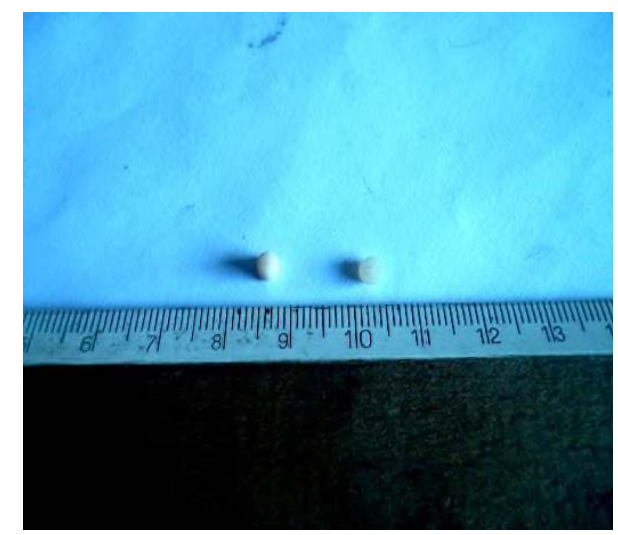

Fig. 1. Polymeric working environments

The vibrating polymer balls, in contact with the surface growing under the action of the chemical component of the combined oxide film process, loosens it, which facilitates the access of the oxidizing chemical solution to the metal surface. The reactivity of the solution is enhanced by the activation of its constituent components.

The intensity of the ongoing processes is noted not only in the reaction zone, but also in the zone of direct contact. Under the influence of normal and tangential forces, the surface layer of the oxide film changes due to the vibrational mechanical action of the system. 
Shear processes of elastoplastic deformation include the sliding mechanism, which manifests itself in the movement of one part of the grain in relation to another. Outwardly, the manifestation of this movement is expressed by the formation of slip bands on the metal surface [21-25].

Figure 1 shows the structure of the AD1 aluminum alloy before and after processing.

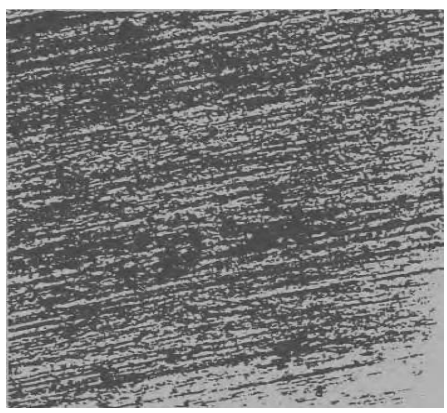

a)

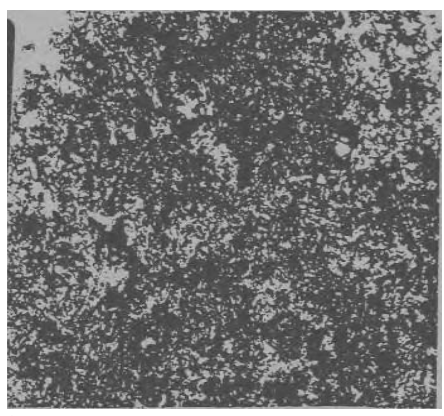

b)

Fig. 2. Structure of aluminum alloy AD1 (x 220): a-initial; b - after application in vibration treatment

Typical traces of processing the polished surface of the aluminum alloy AD1 in polyethylene balls are seen in Fig. 2.

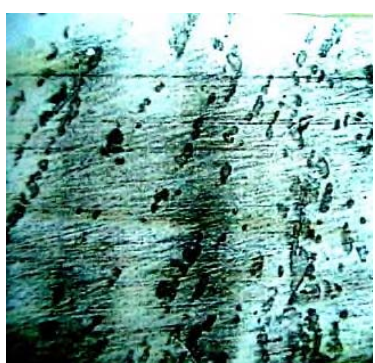

a)

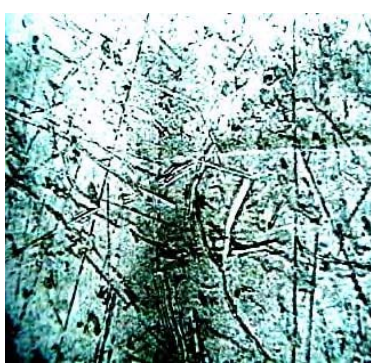

b)

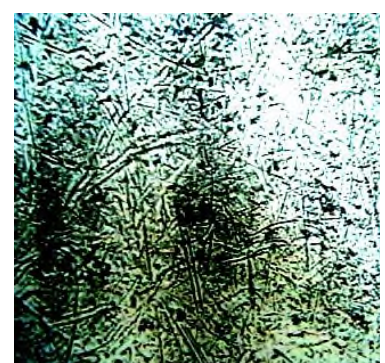

c)

Fig. 3. The traces on the aluminum alloy AMC after vibration treatment in the environment of plastic balls. Increase-X 200. a-the original polished sample; b - after 15 minutes of treatment; $b$-after 30 minutes of treatment

Analysis of the photographs shows that when evaluating the roughness, which determines the operational properties of the product, on the surface under study there is a large number of randomly located processing traces - protrusions and depressions. They come in a variety of shapes, depths and sizes. Shallow depressions and longitudinal multidirectional marks of various shapes and sizes are visible, which is a consequence of direct and oblique impacts of the polymer working medium. The contours of the tracks are uneven, which indicates the variable nature of the movement of the polymer ball relative to the treated surface. [30-31].

When examining photographs of the surface of the samples processed for 15 minutes, the heterogeneity of the surface layer of the treated surface is noted. There are polished areas of the surface and areas with signs of destruction. With a longer treatment ( $35 \mathrm{~min})$, contact and the overlap of many single traces on the metal surface are observed. When examining the processed traces, it can be seen that individual polymer balls, when interacting with the treated surface, leave on it an intermittent trace, consisting of smaller traces due to the nature of the movement of the balls. With such a cross pattern of the arrangement of the considered traces of processing, a kind of microrelief is formed, which affects the quality of the vibration chemical-mechanical coating. 
Analyzing the results obtained, it can be noted that when applying a vibrational chemical-mechanical oxide coating, elongated traces are formed on the coating surface, resulting from the sliding of the ball relative to the treated surface, and mixed-type traces, which are the result of both sliding and direct impact.

The large number of traces covering almost the entire surface of the sample indicates the occurrence of processes of elastoplastic deformation at the micro/nanoscale and loosening of surface layer of the natural oxide film. These phenomena are of great importance in the formation of an oxide film and surface microrelief, since direct contact of the ball occurs along the oxide film [5-8].

Numerous studies have established the presence of plastic flow of the material in a thin surface layer of the sample in the direction of movement of an individual granule, therefore, with a direct impact of a polyethylene ball, the deformation is directed deep into the sample. Most of the marks are inherent to the impact of balls directed at an angle to the surface, which cause brittle destruction of the oxide and shear of individual particles. Such interaction with the surface allows loosening of the oxide layer with the formation of fine particles, which accelerates chemical processes [26-30]. Some of the particles are seized by their juvenile surfaces with oxide, sometimes getting into the pores and reducing their volume, partially carried away by the oxidizing solution, and partially compacted by subsequent blows of polyethylene balls. Consequently, as a result of vibration wave action, the oxide film is loosened and smoothed during its growth. [32-34].

In the contact zone, due to the sliding impacts of the polyethylene balls, there is some displacement of the growing coating towards the rotation of the working medium (Fig. 3).

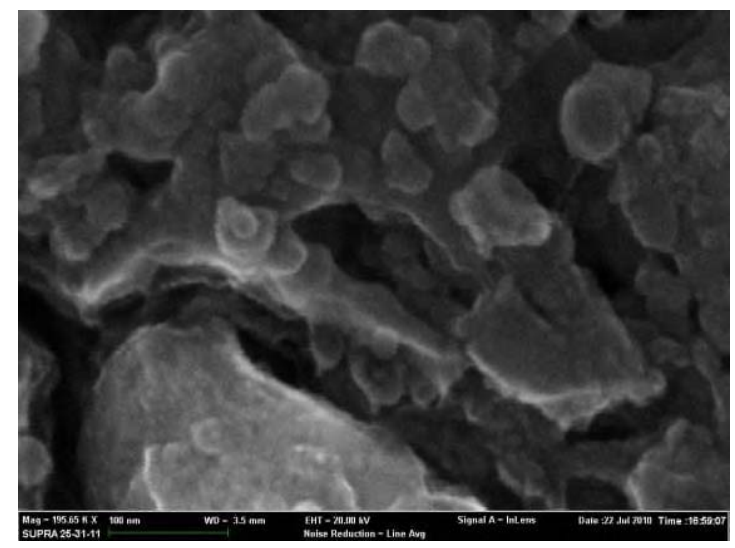

Fig. 4. The morphology of vibrational chemical-mechanical oxide layer: $\mathrm{T}=20 \mathrm{~min}, \mathrm{AA}=2 \mathrm{~mm}$, scale is $100 \mathrm{~nm}$

Studies of the surface morphology of a vibrational chemical-mechanical oxide coating revealed the growth stages and dimensions of the oxide film obtained as a result of the deposition of an AL9 grade aluminum alloy on a polished surface under modes: vibration amplitude $\mathrm{A}=2 \mathrm{~mm}$ and frequency $\mathrm{f}=33 \mathrm{~Hz}$, time 5, 10, $20 \mathrm{~min}$ [10-13]. The original aluminum surface is shown in Fig. 5 (scale 10 and $1 \mu \mathrm{m}$ ). The study of the coating surface at the micro / nanoscale was carried out on a Zeiss SUPRA25 analytical field emission electron microscope. Longitudinal lines are visible on the surface after machining with a thickness of up to 1 micron. 


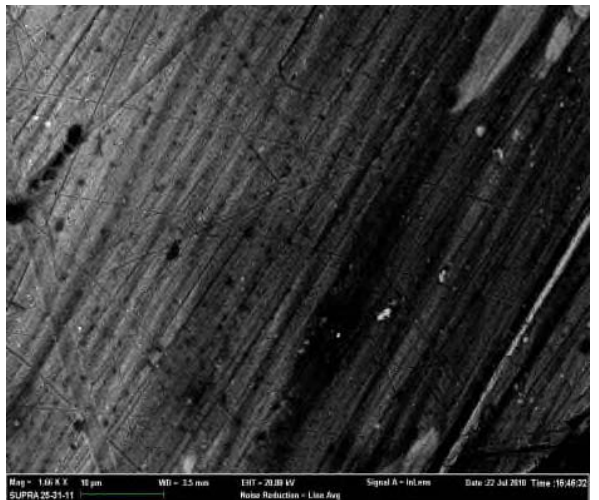

a)

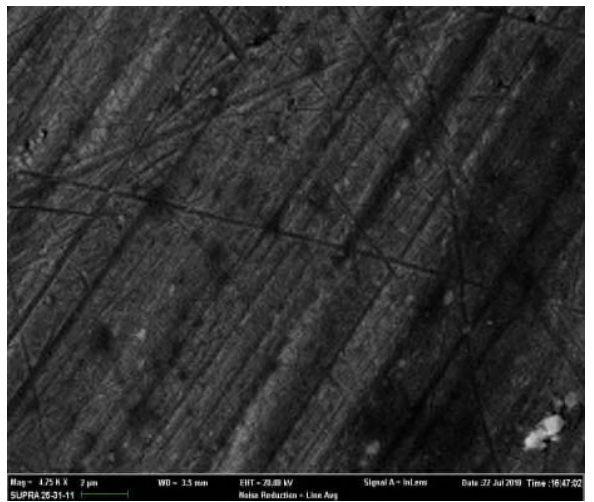

b)

Fig. 5. The original surface of the aluminum alloy AL 9. Scale: $-10 \mu \mathrm{m} ; \mathrm{b}-2 \mu \mathrm{m}$

In fig. $6 \mathrm{a}$ and $6 \mathrm{~b}$ it can be seen that the traces after polishing of the samples do not overlap before coating. The formation of a vibrational chemical-mechanical oxide coating at the micro level occurs on the metal surface in such a way that the coating copies the relief of the original surface, as evidenced by contrasting stripes. In fig. 6c,d (scale 200 $\mathrm{nm}$ ), shape and size of the oxide coating nucleus is clearly visible, it is found that not all cells have oval shape, sizes range from 10 to $50 \mathrm{~nm}$.

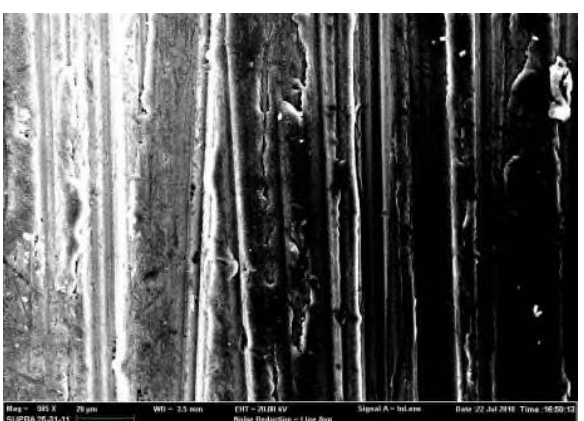

a)

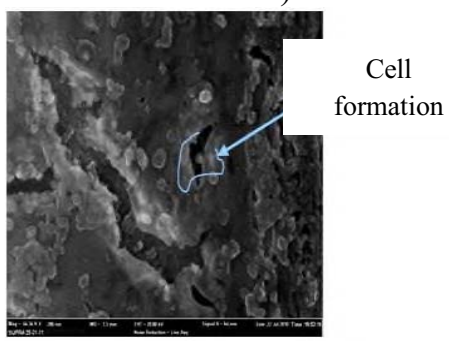

c)

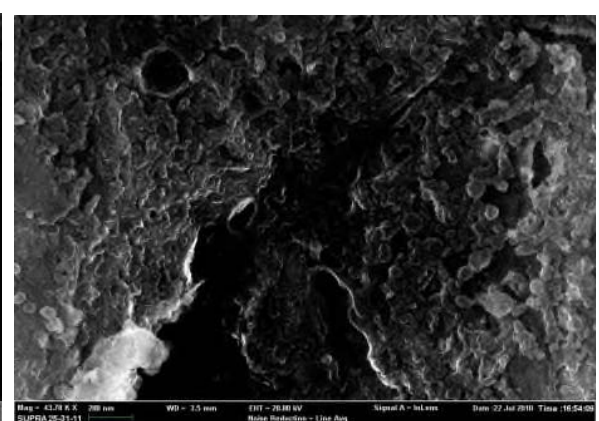

b)

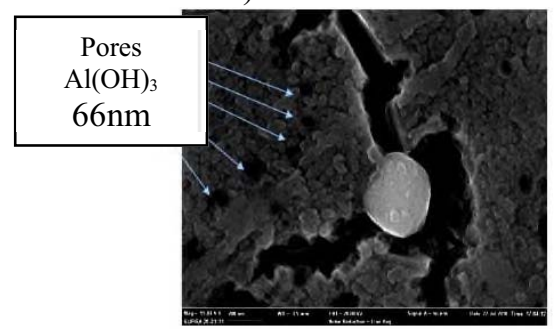

d)

Fig. 6. Surface morphology of vibrational chemical mechanical oxide coating. Application time 5 min. Scale: a-20 microns; b-200 nm; b -200 nm; g -200 nm;

The conducted studies allow us to conclude that the use of polyethylene working media is advisable to use for the formation of vibrating chemical-mechanical oxide coatings. Which by the protective ability is 1.5 times higher than the oxide film obtained by the standard method. 


\section{Conclusions}

1. It was found that the optimal modes of formation of a vibrational chemical-mechanical oxide coating (vibration amplitude $-2.5 \mathrm{~mm}$, vibration frequency $-16-35 \mathrm{~Hz}$, processing time - $15 \mathrm{~min}$, working medium - polyethylene balls D 2-2.5 mm) make it possible to obtain a coating with a thickness of $5 \mu \mathrm{m}$ with no hydrogenated surface coating layer.

2. A relationship was established between the state of the original surface and the performance of parts after applying a vibrational chemical-mechanical oxide coating, which made it possible to adjust the technological modes and the technological process of manufacturing high-resource parts with coatings.

\section{References}

1. V. V. Ivanov, N. P. Pogorelov, N. S. Dontsov, Y. N. Denisenko, AIP Conference Proceedings, 2188, 020005 (2019) doi.org/10.1063/1.5138379

2. V. A. Lebedev, V. V. Ivanov, V. P. Fedorov, Materials Science and Engineering, 124 (2016) doi.10.1088 / 1757-899X /124/1/012160.

3. V. P. Smolentsev, A. I. Portnykh, V. V. Ivanov, IOP Conf. Series: Materials Science and Engineering, 327, 042121 (2018) doi: 10.1088 / 1757-899X/327/4/042121

4. A. A. Korotky, E. V. Marchenko, S. I. Popov, Ju. V. Marchenko, N. S. Dontsov, Theoretical foundations of modeling the process of transport vehicles steel ropes structural defects formation. XIII International Scientific and Practical Conference "State and Prospects for the Development of Agribusiness - INTERAGROMASH 2020»: $\quad E 3 S \quad W e b \quad$ of Conferences, 175, $05018 \quad$ (2020) doi.org/10.1051/e3sconf/202017505018

5. V. V. Ivanov, S. I. Popov, N. S. Dontsov, G. E. Ekinil, Ju. A. Oleynikova, Ju. N. Denisenko, Mechanical coating formed under conditions of vibration exposure. XIII International Scientific and Practical Conference «State and Prospects for the Development of Agribusiness - INTERAGROMASH 2020»: E3S Web of Conferences, 175, 05023 (2020) doi.org/10.1051/e3sconf/202017505023

6. A. A. Korotky, S. I. Popov, G. A. Galchenko, Ju. V. Marchenko, D. S. Drozdov, The use of SmartBox container for agrobusiness logistic processes optimization. XIII International Scientific and Practical Conference «State and Prospects for the Development of Agribusiness - INTERAGROMASH 2020»: E3S Web of Conferences, 175, 13019 (2020) doi.org/10.1051/e3sconf/202017513019

7. V. V. Ivanov, S. I. Popov, E. M. Selemeneva, N. T. Babazhanov, Study of technological characteristics of the process of formation of vibration mechanochemical oxide coating. XV International scientific-technical conference «Dynamics of technical systems» (DTS-2019): AIP Conference Proceedings, 2188, 020015 (2019) doi.org/10.1063/1.5138389

8. V. V. Ivanov, S. I. Popov, Ju. V. Marchenko, E. V. Marchenko, N. S. Dontsov, S. A. Timofeev, Thickness of vibrational mechanochemical solid-lubricant coating in friction pairs of transport engineering products. XII International Scientific Conference on Agricultural Machinery Industry (INTERAGROMASH 2019): IOP Conference Series: Earth and Environmental Science, 403 (2019) doi:10.1088/1755$1315 / 403 / 1 / 012115$

9. A. A. Korotky, E. V. Marchenko, V. V. Ivanov, S. I. Popov, Ju. V. Marchenko, N. S. Dontsov, Model of forming vibration mechanochemical solid lubrication coating on surface of steel rope. XII International Scientific Conference on Agricultural 
Machinery Industry (INTERAGROMASH 2019): IOP Conference Series: Earth and Environmental Science, 403 (2019) doi:10.1088/1755-1315/403/1/012116

10. A. A. Kotesova, S. V. Teplyakova, S. I. Popov, F. C. Kopylov, Ensuring assigned fatigue gamma percentage of the components. International Scientific Conference "Construction and Architecture: Theory and Practice of Innovative Development» (CATPID-2019): IOP Conference Series: Materials Science and Engineering, 698 (2019) doi:10.1088/1757-899X/698/6/066029

11. V. V. Ivanov, N. P. Pogorelov, N. S. Dontsov, Y. N. Denisenko, Research of the metal coating transition zone and the definition of the vibrational chemical-mechenical zinc coating characteristics // XV International scientific-technical conference "Dynamics of technical systems» (DTS-2019): AIP Conference Proceedings, 2188, 020005 (2019) doi.org/10.1063/1.5138379

12. V. V. Ivanov, V. Lebedev, I. Davydova, T. Atoyan, Analysis of the zinc covering quality formed by the vibration chemical-mechanical synthesis. MATEC Web of Conferences, 132 (2017) DOI: 10.1051/matecconf/201713201003

13. V. V. Ivanov, A. P. Babichev, N. P. Pogorelov, The research of technological characteristic of the vibrowave mechanical and chemical oxide coating formation. MATEC Web of Conferences, 132 (2017) DOI: 10.1051/matecconf/201713201004

14. N. N. Nikolaev, Yu. V. Marchenko, S. K. Filatov, Research and modeling of the taxi service in small towns. International Scientific Conference «Construction and Architecture: Theory and Practice of Innovative Development» (CATPID-2019): IOP Conference Series: Materials Science and Engineering, 698 (2019) doi:10.1088/1757$899 \mathrm{X} / 698 / 6 / 066027$

15. V. Ilyasov, B. Meshi, D. Pham, C. Nguyen, O. Holodova, T. Zhdanova, I. Ershov, N. Prutsakova, I. Popova, Springer Proceedings in Physics, 207, 127-144 (2018) doi:10.1007/978-3-319-78919-4

16. A. Altybayev, A. Zhanbyrbayev, B. Meskhi, D. Rudoy, A. Olshevskaya, A. Prohorova, E3S Web of Conferences, 135, 01078 (2019) https://doi.org/10.1051/e3sconf/201913501078.

17. B. Meskhi, B. Golev, V. Efros, D. Rudoy, A. Olshevskaya, V. Zhurba, Y. Chayka, E3S Web of Conferences, 135, 01083 (2019) https://doi.org/10.1051/e3sconf/201913501083

18. A. A. Kostoglotov, I. V. Pugachev, A. A. Yachmenov, S. V. Lazarenko, Synthesis of Intelligent Discrete Algorithms for Estimation with Model Adaptation Based on the Combined Maximum Principle. Advances in Intelligent Systems and Computing, 874, 116-124 (2019) Vol. URL: https://link.springer.com/chapter/10.1007/978-3-03001818-4_12. DOI: 10.1007/978-3-030-01818-4_12.

19. S. V. Lazarenko, A. A. Kostoglotov, A. I. Kostoglotov, Synthesis of Adaptive Tracking Systems Based on the Hypothesis of Stationarity of the Hamiltonian on the Switching Hypersurface. Journal of Communications Technology and Electronics, 54(4), 431-438 (2009) DOI: 10.1134/S1064226909040081.

20. A. A. Kostoglotov, D. S. Andrashitov, A. S. Kornev, S. V. Lazarenko, A Method for Synthesis of Algorithms to Estimate the Dynamic Error of Measurement System Software on the Basis of the Combined Maximum Principle. Measurement Techniques. 62, 497-502 (2019) DOI: 10.1007/s11018-019-01652-8

21. S. I. Kambulov, I. V. Bozhko, A. V. Olshevskaya, MATEC Web of Conferences, 224, 05022 (2018) https://doi.org/10.1051/matecconf/201822405022

22. J. Gerber, A. Zavaly, A. Gavrilov, A. Olshevskaya, N. Kiyan, IOP Conf. Series: Earth and Environmental Science, 403, 012014 (2019) doi:10.1088/1755-1315/403/1/012014 
23. T.Rogovenko, M. Zaitseva, MATEC Web of Conferences, 129, 05014 (2017) doi.org/10.1051/matecconf/201712905014

24. V. Kasyanov, V. Deryushev, L. Shulkin, E. Kosenko, A. Kotesova, MATEC Web of Conferences, 224, 02107 (2018) doi.org/10.1051/matecconf/201822402107

25. T. Rogovenko, M. Zaitseva, Materials Science Forum, 931, 417-421 (2018) doi.org/10.4028/www.scientific.net/MSF.931.417

26. B. Yu. Kalmykov, S. G. Stradanchenko, A. Y. Sirotkin, A. S. Garmider, Y. B. Kalmykova, ARPN Journal of Engineering and Applied Sciences, 11(17), 1020510208 (2016)

27. I. Y. Visotski, N. A. Ovchinnikov, I. M. Petriashvili, Y. B. Kalmikova, B. Yu. Kalmykov, ARPN Journal of Engineering and Applied Sciences, 10(12), 5150-5156 (2015)

28. B. Yu. Kalmykov, N. A. Ovchnnikov, O. M. Kalmikova, I. K. Guguyev, I. V. Kushnariva, ARPN Journal of Engineering and Applied Sciences, 10(10), 4366-4371 (2015)

29. N. A. Ovchinnikov, B. Yu. Kalmykov, S. G. Stradanchenko, E. A. Kozyreva, O. V. Chefranova, ARPN Journal of Engineering and Applied Sciences, 10(22), 1051110522 (2015)

30. B. Yu. Kalmykov, N. A. Ovchinnikov, O. M. Kalmikova, V. I. Jigulskii, Y. G. Yurshin, ARPN Journal of Engineering and Applied Sciences, 10(8), 3793-3797 (2015)

31. Yu. A. Ivanov, V. I. Pakhomov, S. I. Kambulov, D. V. Rudoi, (ICMTMTE 2018) electronic edition. Cep. MATEC Web of Conferences, 224, 05023 (2018) https://doi.org/10.1051/matecconf/201822405023

32. E. Zubrilina, I. Markvo, V. Novikov, A. Beskopylny, L. Vysochkina, D. Rudoy, A. Butovchenko, IOP Conf. Series: Earth and Environmental Science, 403 (2019) 012063 doi:10.1088/1755-1315/403/1/012063

33. A. Altybayev, Y. Naydenko, B. Meskhi, A. Mozgovoy, D. Rudoy, A. Olshevskaya, E3S Web of Conferences, 175, 03019 (2020) INTERAGROMASH 2020 https://doi.org/10.1051/e3sconf/202017503019

34. G. Parkhomenko, I. Bozhko, S. Kambulov, A. Boyko, O. Polushkin, V. Lebedenko, A. Beskopilniy, A. Olshevskaya, E3S Web of Conferences, 175, 09006 (2020) INTERAGROMASH 2020 https://doi.org/10.1051/e3sconf/202017509006 